\title{
Correspondence
}

Contents: Psychiatry and the concept of evil/OGS or tardive dystonia?/Huntington's disease in the Oxford region/Anaesthetic technique in the practice of ECT/Counselling and community psychiatric nurses/Home- v. hospital-based care for people with serious mental illness/Investigating multiple personality disorder/A spiritual dimension to mental illness

\section{Psychiatry and the concept of evil}

SIR: The editorial by Prins and the comment by His Hon. Judge Jones (BJP, September 1994, 165, 297-302) was of great interest and I found myself at one with Judge Jones in accepting the notion of there being "evil/sane people", "good/sane people" and "good/mentally ill people" but I am rather less certain about a fourth category of "evil/mentally ill people". My uncertainty regarding the category of "evil/mentally ill people" causes me to consider the matter of what is a mental illness.

I am somewhat surprised that neither Prins or Jones advert to the concept of "psychopathy" or "psychopathic disorder" or the "personality disorders" (there are eleven subgroups noted in DSM-IV).

In this State (Victoria) the diagnosis of a personality disorder has been deemed to be not a mental illness or someone being mentally ill. This state of affairs has not arisen in relation to legislation but is due to a finding by the Mental Health Review Board (Mental Health Act (Vict.) 1986 ss $21-46$ in a case of Attorney-General v. David [1992] 2 V.R. 46-96, and Kiel, 1992). The finding in the case of David relates to all personality disorders including the antisocial and borderline states. The position in England and Wales seems to differ - not only are the various conditions seen as mental illnesses but will allow of certification in appropriate cases, whereas in Victoria extra-ordinary legislation was passed in order to deal with the notion of dangerousness (Bartholomew, 1992).

If personality disorder is not an illness then much "evil" behaviour will not be an illness and so remain designated as being "evil/sane people"; this in Victoria but not in England and Wales. The problem for the psychiatrist is to attempt to disentangle "evil" from "illness" and this is the task which Jones quite properly hands to the psychiatrist. It is right and proper that the psychiatrist may research the question "Is this person mentally ill?" and if such person is mentally ill ask the further question "How can I treat this person?". But what if there is an untreatable illness. Is it appropriate to incarcerate in terms of "care"?

BArtholomew, A. A. (1992) Dangerousness: A Novel Approach. Psychiatric Bulletin, 16, 299-300.

KIEL, H. (Ed.) (1992) Decisions of the Mental Health Review Board Victoria 1987-1991. Melbourne (1992), Cases 20, 21 pp. 147-159-207 Both cases were "Appeals".

Suite 1, 8th Floor

A. BARTHOLOMEW

118 Queen Street

Melbourne 3000

SIR: In matters of evil and of distinguishing madness and badness, Prins and Jones (BJP, September $1994,165,297-302)$ agree with the old rhyme's dictum that "doctors should attend the sick and leave the well alone". Or in this case, that we should leave the evil-well to other professions.

But no specialism, science or profession is an island. Medicine employs its science in the greater cause of helping and healing. To heal the sick especially where mental healing is our speciality and there is an IC "Disease" diagnostic category for almost everything that moves - requires a knowledge of well-functioning, and expertise that enables a person's return to it. Sickness is only a part of the whole situation we work with. The wider context of the future and of a knowledge of healthy functioning - is an integral part of our immediate attention to the unhealthy.

In legal contexts, the psychiatrist's required preoccupation may be with the adult legal question of the accused's knowing the difference between right and wrong. This may be basic to the pursuit of justice. But it creates considerable difficulties in that it is also a partial matter that prevents us addressing the whole situation, including a contribution to 
future planning for the clients as of the legal system. This is true for adults as well as for children as in the Bulger case that Prins and Jones discuss.

For example, if the legal system allowed a broader remit for the psychiatrists in the Sutcliffe trial, then it would have been a much simpler matter to resolve the "disposal" of the case. Society and Sutcliffe needed him to be contained for a length of time that was more than just an expression of our understandable wish to punish his "evil". Of the options available, a hospital has since been shown to be more appropriate than prison. This conclusion could have been reached in court virtually without reference to matters of psychiatric diagnosis and treatment. Of course, if he could be cured of something, then the length of time served might turn out to be shorter than a prison sentence.

The idea of integrated future planning by all involved, and for the best interests of one and all, is the basis of the Scottish Childrens Hearing system. Generally, once it is briefly accepted by everyone that there are some grounds for the Hearing, the whole process is then devoted to discussing what needs to be planned for thereafter. The adult courts have a back-up role, and they would have been employed in a case as serious as the Bulger one. But I believe Scottish common sense and moderation would have limited the backward-looking excesses of the English system.

Philosophically, the problem requires a radically different starting point about human nature. The typical Western dualistic - schizoid even - philosopher's position is of "man the thinker" thinking about (and then trying to mobilise himself problematically into) the separate "world out there". An alternative assumption is the more integrating one that a human being exists primarily in time and action/interaction (and reflection), constituting the "self as agent" and "persons in relation". These are the titles of a pair of books by the (Scots) philosopher John Macmurray (1957 \& 1961) who systematically explored philosophical questions from this new starting point. From this kind of view of normal human functioning, a new understanding of (physical and) mental illness can be derived, for example, as "action failure" (Fulford, 1989).

Through all of this run two themes: first, that yet-to-be-realised "causes" which lie in the future, set the course we humans and professionals determine to follow, as much as or more than the already-realised past does; and second, that doctors cannot tend the sick properly if they leave the well alone. In our science, in our healing, and when we advise the courts, we do better when we address the whole situation, including the futures that all those involved may intend.

FulforD, K. W. M. (1989) Moral Theory and Medical Practice. Cambridge: Cambridge University Press. Macmurray, J. (1957) The Self as Agent. Faber. Macmurray, J. (1961) Persons in Relation. Faber.

Child and Family Clinic

N. CHILD

49 Airbles Road

Motherwell ML1 2TJ

SIR: Invoking the concept of "evil", as some externally imposed force, or inborn trait, serves only to absolve everyone from responsibility for it, and implies that it is fixed and, therefore, untreatable.

People who commit brutal acts usually do so either because they are psychotic, or they have been brutalised. I would suggest that the latter are the result, mainly, of pathological nurture and have little to do with nature, unless organic brain damage is involved.

The James Bulger case has caused children in general to be demonised. They are being irrationally scapegoated for the sins of society.

Children with severe emotional disturbance are, however they present, the damaged product of an adult society which has failed them. As to the ability to distinguish between right and wrong, this distinction is not imbibed with the milk, but learned by example from the adults who are responsible for the care of children. If the messages received are too inappropriate, inconsistent or conflicting, children will develop a pathological perspective on their world.

All children are dependent for their mental and physical welfare on adults, and are vulnerable and very impressionable. Disturbed children are often very emotionally immature for their age and, as a result, even less responsible for their actions. The point is not simply recognising whether something is right or wrong, but having the capacity to make the correct choices, and to appreciate the implications of making the wrong ones. The chronological age of the child alone does not determine this capacity, it is the maturity and quality of his or her emotional adjustment together with intellectual endowment, sense of self-worth and self-confidence.

The inclination to do wicked things may exist "in the hearts of men" but man is sufficiently malleable, given the right influences, to be taught to control such aggression and redirect it constructively. To develop such a capacity children rely on adults. Any 